Research Article

\title{
Evaluation and Implementation of a Shunt Active Power Filter under balanced Source Voltages
}

\author{
P.M.Balasubramaniam ${ }^{1, *}$ and G. Gurusamy ${ }^{2}$ \\ Dpt of Electrical \& Electronics Engineering,KKIT, Coimbatore, India. \\ Dean, Bannari Amman Institute of Technology, Sathy, India.
}

Received 21 June 2012; Accepted 25 September 2012

\begin{abstract}
The Shunt Active Power Filter has proved to be a useful device to eliminate harmonic currents and to compensate reactive power for nonlinear loads. The basic principle of operation of a Shunt Active Power Filter is to inject a suitable non-sinusoidal current (compensating current) into the system at the point of common coupling. An current control algorithm based on the time-domain approach for three-phase Shunt Active Power Filters is analyzed in this paper. A basic overview and evaluation of the performance of existing algorithms for active power filters are presented. According to different complicated power quality issues and various compensation purposes, a current control scheme based on time domain approach is proposed. Comparing with existing algorithms; this algorithm has shorter response time delay. Different compensating current references can thus, be accurately and easily obtained by adopting the proposed algorithm. Simulation results using MATLAB / Simulink have proven excellent performance of the proposed system and it is more effective than the available approaches.
\end{abstract}

Keywords: Shunt active power filter, Synchronous reference frame, Instantaneous reactive power theory, Point of common coupling.

\section{Introduction}

Electric power generated by the utilities is distributed to the consumer in the form of $50 \mathrm{~Hz}$ ac voltage. The utilities have a tight control on the design and operation of the equipment used for transmission and distribution, and can therefore keep frequency and voltage delivered to their customers within close limits. Unfortunately, increasing portions of loads connected to the power system are comprised of power electronic converters. These loads are nonlinear and inject distorted currents in the network and consequently generate harmonic voltage waveforms. With the proliferation of nonlinear loads such as diode/thyristor rectifiers, non-Sinusoidal currents degrade power quality in power transmission/distribution systems. Notably, voltage harmonics in power systems are becoming a serious problem for both utilities and customers. The distortion, whether it is produced by a large single source or by the cumulative effect of many small loads, often propagates for miles along distribution feeders. As the use of non-linear power equipment is spreading, the degradation of the power quality in the utility networks is increasing and is becoming a major problem. Limiting the voltage distortion is therefore a concern for both utilities and consumers.

\footnotetext{
* E-mail address: baluanujayen@gmail.com

ISSN: 1791-2377 2012 Kavala Institute of Technology. All rights reserved.
}

The simple block diagram of Fig. 1 illustrates the distortion problem due to harmonic at low and medium power levels. Here, the utility is represented by an ideal ac voltage source in series with lumped impedance representing lines and transformers. The voltage waveform at the point of common coupling is distorted due to harmonic current generated by the non-linear load.

This results in the following effects on the power system components

1. Malfunction of harmonic sensitive loads

2. Increased losses in parallel connected capacitor, transformers and motors

3. Improper operation of protection relays and circuit breakers

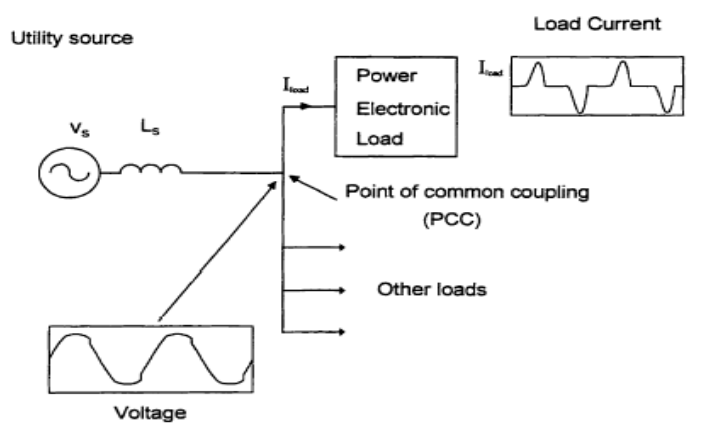

Fig. 1. Harmonic distortion at PCC 


\section{Active Filtering Technology}

The first attempt to reduce harmonics without the use of conventional passive filters was made by B. Bird. This design is based on changing the waveform of the current drawn by the load by injecting a third harmonic current, displaced in phase, into the converter itself. With this method however it is impossible to fully eliminate more than one harmonic.

The next attempt was made by Ametani, which is based on expanding the current injection method by proposing a technique to eliminate multiple harmonics. According to this theory, an active control circuit could be used to precisely shape the injected current. Ideally, this current would contain harmonic components of opposing phase, thus the harmonics would be neutralized, and only the fundamental component would remain. Despite the promising theoretical concept, Ametani was not successful in producing a practical circuit capable of creating a precise current. The total harmonic distortion was reduced, but single harmonics were not completely eliminated. On the other hand, Sasaki and Machida theorized that harmonics could be eliminated by using the principle of magnetic flux compensation. This in principle is the use of current to produce a flux to counteract the flux produced by the harmonics. Once again, theoretically, any number of harmonics could be directly eliminated. The current that would be required to eliminate waveform distortion caused by harmonics was calculated mathematically, but again, a practical control circuit was not realized.

Over the last ten to twelve years the remarkable progress in capacity and switching performance of devices such as Bipolar Junction Transistors (BJT), Gate Turn-Off thyristors (GTO) and Insulated Gate Bipolar Transistors (IGBT), has spurred in the study of active power filters for harmonic compensation. In addition, advances in topologies and control schemes for static PWM converters have enabled active power Filter using these converters to generate specified harmonic currents, such as created by non-linear loads. As active power filters are powerful tools for the compensation not only of current harmonics produced by distorting loads but also of reactive power and unbalance of nonlinear and fluctuating loads. They can be smaller, more versatile, better damped, more selective, and less prone to failure for component drift than its passive counterpart.

\subsection{Shunt Active Filters}

The shunt active filter approach is based on the principle of injection of harmonic currents into the ac system, of the same amplitude but opposite in phase to that of the load harmonic currents. Fig. 2 shows the active power filter compensation principle, which is controlled in a closed loop manner to actively shape the source current into sinusoid.

\subsection{Series Active Filters}

In series active filter configuration, a voltage source, is constructed in such a way that when its voltage is added to the load voltage, the distorted voltage is canceled, thus resulting of a sinusoidal voltage at the Point of Common Coupling (PCC). For harmonic compensation, both shunt and series active filters have smaller ratings than the apparent power of the load. The shunt active filter is rated for supply voltage, but a reduced current. In the case of series dynamic filters, the rated load current passes through the filter but the rated voltage is again lower. Therefore, harmonic minimization can be implemented with converters having a reduced power rating.

\subsection{Hybrid Active Filters}

Hybrid structures were proposed for harmonic compensation of large rated loads in high voltage networks. Hybrid active filters configurations, combines passive and active filters. These filters improve the compensation characteristics of the passive filters and thus realize a reduction in the rating of the active filter. They are particularly suited in installations where L-C tuned passive filters already exist. In the hybrid series configuration, the series voltage injection is to be regarded as an isolator, either determining the harmonic currents to be supplied to the non-linear load or the harmonic currents that will be absorbed by the tuned LCfilters., series and shunt. In the first case, the injected voltage is in series, and in the second case it is in series with the shunt passive filter.

\section{Control Methodology}

Compensation of harmonies can be accomplished in timedomain or frequency domain. First approach is based upon "on line" computation of an instantaneous error function, while the second case uses the principle of Fourier analysis and periodicity of the distorted waveform to be corrected. The error-function in time-domain could be computed in the following ways:

1. Extraction of the fundamental component from the distorted waveform through a notch filter

2. Instantaneous reactive power compensation, which uses an instantaneous orthogonal power transformation on both the actual and the fundamental components of voltage and current to produce a power function. The difference between these two transformations is the error.

3. Synchronous reference frame approach. Many PWM strategies exist (for compensation in the time-domain) to generate the gating signals to the switches and thereby to reconstruct the distorted current. The shunt APFs are used most widely used to cancel the current distortion. The performance of SAPF strictly depends on the features of the improved algorithms and controllers. However, usually one algorithm is only more appropriate to some situation but not to all situation. An improved algorithm of SAPF for harmonic elimination, power factor correction, and balancing of nonlinear loads is proposed in this paper.

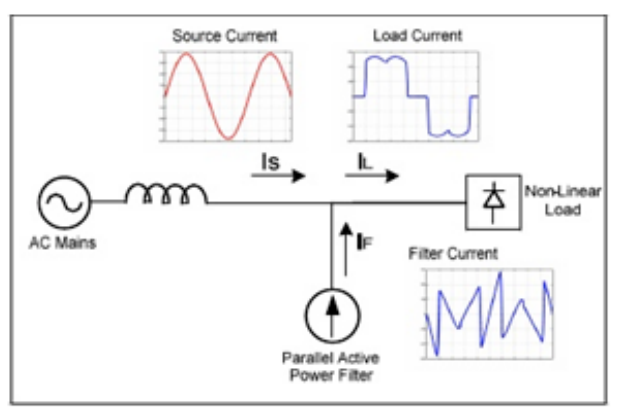

Fig. 2. Basic Principle of SAPF System. 


\section{Simulink Model of The Overall System}

The simulation of power electronic systems provides advantages in the design process by allowing various options. To validate the feasibility of the proposed approach, a virtual implementation of the SAPF is done using Simulink. The main components are the reference compensation current detector, a phase loop lock, a current controller, and dc voltage controller. The reference compensation currents are determined and are given as input to a current controller to produce signals of the PWM inverter. In addition, since the capacitor voltage at the inverter terminal must be maintained at a constant level, the loss caused by switching and capacitor voltage variations is supplied by the source. Simulations show that the compensation current calculator yields negligible time delay in steady state for the SAPF operation.

\section{Mathematical Modelling of the Proposed Method}

In the three-phase three-wire system, the instantaneous load currents of phase "a," "b," "c" $\left(i_{a}, i_{b}\right.$, and $\left.i_{c}\right)$ can be disassembled into positive-sequence and negative-sequence components according to the symmetrical weigh law, which was proposed by Fortes cue separately

$$
i_{x}(n)=\sum_{k=1}^{\infty}\left[I_{1 k} \operatorname{Sin}\left(\frac{2 \pi n k}{N}+\phi_{1 k}-\frac{2 l \pi}{3}\right)+I_{2 k} \operatorname{Sin}\left(\frac{2 \pi n k}{N}+\phi_{2 k}+\frac{2 l \pi}{3}\right)\right](1)
$$

Commonly, only the positive-sequence, negativesequence, active power, and reactive power of the fundamental current are cared, and it is not necessary to decompose the harmonic. Then, the fundamental current component is expressed as follows

$$
\begin{aligned}
i_{x 1}( & n)=I_{11} \operatorname{Sin}\left(\frac{2 \pi}{N} n+\phi_{11}-\frac{2 l \pi}{3}\right)+I_{21} \operatorname{Sin}\left(\frac{2 \pi}{N} n+\phi_{21}+\frac{2 l \pi}{3}\right) \\
= & I_{11} \operatorname{Sin}\left(\frac{2 \pi}{N} n-\frac{2 l \pi}{3}\right) \operatorname{Cos} \phi_{11} \\
& +I_{11} \operatorname{Cos}\left(\frac{2 \pi}{N} n-\frac{2 l \pi}{3}\right) \operatorname{Sin} \phi_{11} \\
& +I_{21} \operatorname{Sin}\left(\frac{2 \pi}{N} n-\frac{2 l \pi}{3}\right) \operatorname{Cos}\left(\phi_{21}-\frac{2 l \pi}{3}\right) \\
& +I_{21} \operatorname{Cos}\left(\frac{2 \pi}{N} n-\frac{2 l \pi}{3}\right) \operatorname{Sin}\left(\phi_{21}-\frac{2 l \pi}{3}\right)
\end{aligned}
$$

where, the first item of (2) corresponds to the positivesequence component in phase with the phase voltage, which is called the active power component of the positivesequence fundamental current; the second item of (2) corresponds to the positive-sequence component orthogonal with the line voltage, which is called the reactive power component of the positive-sequence fundamental current; the third item of (2) corresponds to the negative-sequence component in phase with the line voltage, which is called the active power component of the negative-sequence fundamental current; the forth item of (2) corresponds to the negative-sequence component orthogonal with the line voltage, which is called the reactive power component of the negative sequence fundamental current.

Fig. 4 shows the block diagram of the proposed currentdetection algorithm, where ' $\operatorname{Sin} \frac{2 \pi}{N} n$ ' is synchronous with the positive-sequence fundamental voltage of phase "a," which determines the calculation precision of active and reactive power components. The low-pass filter used determines the performance of the system. According to different compensation purposes, the segregator will obtain different components expediently, which is superior to the algorithm based on the instantaneous reactive power theory.

\section{Gain Selection}

With the above configuration, the control problem reduces to picking the correct gains for the model of Fig. 4.4 for various operating conditions. Taking the sampling delay into account, the plant is a simple lag along with an integrating element

$$
H_{\text {plant }}=\left(\frac{1}{1+s T_{s}}\right)\left(\frac{U}{s}\right)
$$

where $\mathrm{T}$, is the sampling time. The open-loop transfer function $\mathrm{H}_{01}$ with the controller then becomes

$$
H_{01}=\left(K_{p l l} \frac{1+s T_{p l l}}{s T_{p l l}}\right)\left(\frac{1}{1+s T_{s}}\right)\left(\frac{U}{s}\right)
$$

where $\mathrm{K}_{\mathrm{pll}}, \mathrm{T}_{\mathrm{pll}}$ are the gains associated with the PI regulator. This is a standard control problem very similar to a current controlled speed loop of a drive system where the integral term in the plant mimics the mechanical inertia and the lag element emulates the current control loop. Several methods can be used to select the gains based on the desired performance criteria. Here, the method of symmetrical optimum was used to calculate the regulator gains. According to this method, the regulator gains $\mathrm{K}_{\mathrm{pll}}$ and $\mathrm{T}_{\mathrm{pll}}$ are selected such that the amplitude and the phase plot of $\mathrm{H}_{01}$ are symmetrical about the crossover frequency $\omega_{c}$, which is at the geometric mean of the two corner frequencies of $\mathrm{H}_{01}$. Given a normalizing factor $\alpha$ the frequency $\omega_{\mathrm{c}}, \mathrm{K}_{\mathrm{pll}}, \mathrm{T}_{\mathrm{pll}}$ are related as following

$$
\left.\begin{array}{l}
\omega_{c}=1 /\left(\alpha T_{s}\right) \\
T_{p l l}=\alpha^{2} T_{s} \\
K_{p l l}=(1 / \alpha)\left(1 /\left(U T_{s}\right)\right)
\end{array}\right\}
$$

Substituting (4) into (5) it can be shown that the factor $\alpha$ and the damping factor $\xi$ are related by the relationship

$$
\xi=\frac{\alpha-1}{2}
$$

By changing $\alpha$, the system bandwidth and damping can be controlled.

A three-phase PLL system was developed which is suitable for time domain analysis under distorted utility conditions and it was tuned the control effects such as loss of gain, line harmonics, and frequency disturbances. The PLL was completely implemented in software without the use of any hardware filters. When the reference $u_{d e}{ }^{*}$ is set to zero, the $\theta^{*}$ calculated is synchronous with the positive-sequence component of fundamental voltage. When $u_{d e}{ }^{*}$ is not set to zero, a fixed phase difference is between the $\theta^{*}$ and the positive-sequence component of fundamental voltage, which make the control of the displacement factor easy. Moreover, 
this phase difference will not affect the validity of the selected harmonics detection. The corresponding simulation diagram of the PLL is shown in Fig. 5.

The phase voltage is expressed by per-unit; the base quantities for per-unit value are the peak value of positivesequence fundamental phase voltage. Then, three phase voltages can be expressed as, respectively. The instantaneous power of the fundamental current can be obtained by multiplying current by phase voltage $\operatorname{Sin}\left(\frac{2 \pi}{N} n-\frac{2 l \pi}{3}\right)$

$$
\begin{aligned}
& i_{x 1}(n) * \operatorname{Sin}\left(\frac{2 \pi}{N} n-\frac{2 l \pi}{3}\right) \\
& =\frac{1}{2}\left\{I_{11} \operatorname{Cos} \phi_{11}\left[1-\operatorname{Cos}\left(\frac{4 \pi}{N} n-\frac{4 l \pi}{3}\right)\right]\right. \\
& +I_{11} \operatorname{Sin} \phi_{11} \operatorname{Sin}\left(\frac{4 \pi}{N} n-\frac{4 l \pi}{3}\right) \\
& +\mathrm{I}_{21} \operatorname{Cos}\left(\phi_{21}-\frac{2 l \pi}{3}\right)\left[1-\operatorname{Cos}\left(\frac{4 \pi}{N} n-\frac{4 l \pi}{3}\right)\right]
\end{aligned}
$$

where the first item of the equation corresponds to the instantaneous active power component of the positivesequence fundamental (the sum of three phases is constant, which contributes to the total power delivered from source to load). The second item of the equation corresponds to the instantaneous reactive power component of the positivesequence fundamental (the sum of three phases is zero, which circulates between the phases and can be compensated by a compensator without an energy storage element). The third item corresponds to the instantaneous active power component of the negative-sequence fundamental (the three-phase sum of the previous part of this item is zero, which circulates between the phases and can also be compensated by a compensator without an energystorage element). The three-phase sum of the rest (including the posterior part of the third and fourth items, which is equal to $-I_{21} \operatorname{Cos}\left(\frac{4 \pi}{N} n-\varphi_{21}\right)$ and the same for each phase) is not zero, and its frequency is twice the fundamental, which can be compensated by a compensator with an energy-storage element). Therefore, the negativesequence fundamental currents do not contribute to the power delivered to the load. Similarly, the instantaneous power of harmonics can be obtained by multiplying current by

$$
\begin{aligned}
& i_{x k}(n)= \\
& \frac{1}{2}\left\{I_{1 k}\left[\operatorname{Cos}\left(\frac{2 n \pi}{N}(k-1)+\phi_{1 k}\right)-\operatorname{Cos}\left(\frac{2 n \pi}{N}(k+1)+\phi_{1 k}+\frac{2 l \pi}{3}\right)\right]\right. \\
& \left.+I_{2 k}\left[\operatorname{Cos}\left(\frac{2 n \pi}{N}(k-1)+\phi_{2 k}-\frac{2 l \pi}{3}\right)-\operatorname{Cos}\left(\frac{2 n \pi}{N}(k+1)+\phi_{2 k}\right)\right]\right\}
\end{aligned}
$$

It can be seen that either the negative-sequence or positive-sequence component has one part of which the three-phase sum up to zero, which can be compensated by a compensator without energy storage, and the rest can be compensated by a compensator with energy storage.

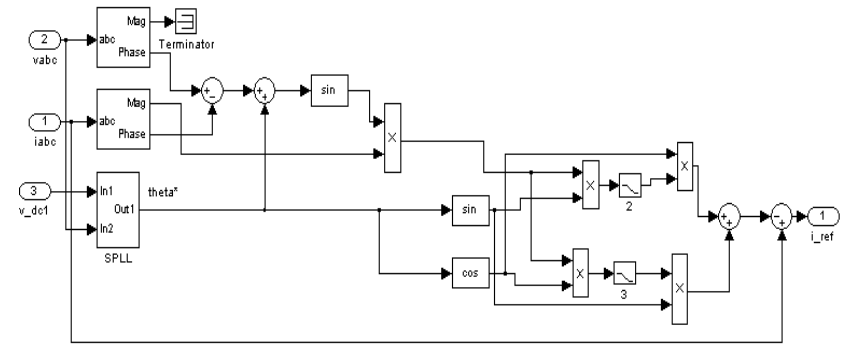

Fig. 3. Simulation diagram of the current control algorithm.

In (7) and (8), the lowest frequency component is twice the fundamental frequency; the dc component can be obtained by a low-pass filter with a cutoff frequency lower than twice the Fundamental frequency or by a slidingwindow with $N / 2$ samples. Then, multiplying by 2 , the following equation can be obtained:

$$
B_{x 1}=I_{11} \operatorname{Cos} \phi_{11}+I_{21} \operatorname{Cos}\left(\phi_{21}+4 l \pi / 3\right)
$$

Multiplying (1) $\operatorname{Cos}\left(\frac{2 \pi}{N} n-\frac{2 l \pi}{3}\right)$ the following equation can be obtained

$$
\begin{aligned}
& i_{x}(n) * \operatorname{Cos}\left(\frac{2 \pi}{N} n-\frac{2 l \pi}{3}\right)= \\
& \frac{1}{2}\left\{I_{11}\left[\operatorname{Sin} \phi_{11}+\operatorname{Sin}\left(\frac{4 \pi}{N} n+\phi_{11}-\frac{4 l \pi}{3}\right)\right]\right. \\
& \left.+I_{21}\left[\operatorname{Sin}\left(\frac{4 \pi}{N} n+\phi_{21}\right)+\operatorname{Sin}\left(\phi_{21}+\frac{4 l \pi}{3}\right)\right]+i_{h}\right\}
\end{aligned}
$$

Using the same method, the following equations can also be obtained

$$
A_{x 1}=I_{11} \operatorname{Sin} \varphi_{11}+I_{21} \operatorname{Sin}\left(\varphi_{21}+4 l \pi / 3\right)
$$

Here, define

$$
\left(\begin{array}{ll}
A_{11} & B_{11} \\
A_{21} & B_{21}
\end{array}\right)=\left(\begin{array}{ll}
I_{11} \operatorname{Sin} \varphi_{11} & I_{11} \operatorname{Cos} \varphi_{11} \\
I_{21} \operatorname{Sin} \varphi_{21} & I_{21} \operatorname{Cos} \varphi_{21}
\end{array}\right)
$$

where $A_{11}$ and $B_{11}$ are the peak values of the reactive power component and active power component of positivesequence fundamental current, respectively. $A_{21}$ and $B_{21}$ are the peak values of the reactive power component and active power component of negative-sequence fundamental current of phase "a," respectively. According to phase " $b$ " and "c," the peak values are $I_{21} \operatorname{Sin}\left(\varphi_{21}-2 \pi / 3\right)$,

$$
I_{21} \operatorname{Cos}\left(\varphi_{21}-2 \pi / 3\right) \quad \text { and } \quad I_{21} \operatorname{Sin}\left(\varphi_{21}+2 \pi / 3\right) \text {, }
$$

$I_{21} \operatorname{Cos}\left(\varphi_{21}+2 \pi / 3\right)$. Respectively, similarly, multiplying $2 \operatorname{Sink}\left(\frac{2 \pi}{N} n-\frac{2 l \pi}{3}\right)$ and $2 \operatorname{Cosk}\left(\frac{2 \pi}{N} n-\frac{2 l \pi}{3}\right)$, respectively, and going through the low-pass filter, $A_{x k}$ and $B_{x k}$ can be obtained: 


$$
\begin{aligned}
& A_{x k}=I_{1 k} \operatorname{Sin}\left[\frac{2(k-1) l \pi}{3}+\varphi_{1 k}\right]+I_{2 k} \operatorname{Sin}\left[\frac{2(k+1) l \pi}{3}+\varphi_{21}\right] \\
& B_{x k}=I_{1 k} \operatorname{Cos}\left[\frac{2(k-1) l \pi}{3}+\varphi_{1 k}\right]+I_{2 k} \operatorname{Cos}\left[\frac{2(k+1) l \pi}{3}+\varphi_{21}\right] \\
& \text { Then, define } \operatorname{Sin}\left(\frac{2 \pi}{N} n-\frac{2 l \pi}{3}\right) \\
& i_{x 11}=A_{11} \operatorname{Cos}\left(\frac{2 \pi}{N} n-\frac{2 l \pi}{3}\right)+B_{11} \operatorname{Sin}\left(\frac{2 \pi}{N} n-\frac{2 l \pi}{3}\right) \\
& i_{x 21}=A_{21} \operatorname{Cos}\left(\frac{2 \pi}{N} n+\frac{2 l \pi}{3}\right)+B_{21} \operatorname{Sin}\left(\frac{2 \pi}{N} n+\frac{2 l \pi}{3}\right) \\
& i_{x 1}=A_{x 1} \operatorname{Cos}\left(\frac{2 \pi}{N} n-\frac{2 l \pi}{3}\right)+B_{x 1} \operatorname{Sin}\left(\frac{2 \pi}{N} n-\frac{2 l \pi}{3}\right) \\
& i_{x k}=A_{x 1} \operatorname{Cos}\left(\frac{2 \pi}{N} n-\frac{2 l \pi}{3}\right)+B_{x k} \operatorname{Sin}\left(\frac{2 \pi}{N} n-\frac{2 l \pi}{3}\right)
\end{aligned}
$$

Equations (11)-(16) compose the separator shown in Fig. 4, by which various results can be achieved according to different compensation purposes. If the SAPF is used to compensate harmonics and the negative-sequence component of the fundamental current, the positive-sequence component of the fundamental current $i_{x 11}$ can be obtained from (14), and the current reference can be obtained as $i_{c x}^{*}(n)=i_{x}^{*}(n)-i_{x 11}(n)$ by subtracting $i_{x 11}$ from the load current. If the line current after compensation is expected to be a symmetrical three-phase fundamental current, and the power factor is 1 , the active power component of the positive-sequence fundamental current $i_{p x 11}$ can be obtained by assuming $A_{11}=0$ in (4.14), and the current reference can be obtained as $i_{c x}^{*}(n)=i_{x}(n)-i_{p x 11}(n)$ by subtracting $i_{p x 11}$ from the load current. Similarly, by setting $B_{11}$ to zero, the reactive power component of the positive-sequence fundamental current can be obtained. The negative-sequence component of the fundamental current can be obtained by (15). If the APF is used to compensate the selected order harmonics, the compensating reference can be obtained by (17). In fact, the "active power" component and "reactive power" component of harmonics do not need to be divided, so the factors $\operatorname{Cosk}\left(\frac{2 \pi}{N} n-\frac{2 l \pi}{3}\right)$ and $\operatorname{Sink}\left(\frac{2 \pi}{N} n-\frac{2 l \pi}{3}\right)$ can be replaced with $\operatorname{Sin}\left(\frac{2 n k \pi}{N}\right)$ and $\operatorname{Cos}\left(\frac{2 n k \pi}{N}\right)$ separately. Then, the programming can be greatly simplified. Based on the detection methods, different compensation aims can be achieved by using specific combinations.

\section{Simulink Model of the Improved Algorithm}

The main components of the current detection algorithm include a Phase Loop Lock, a sine wave generator and the separator. The current detection algorithm is implemented according to the proposed strategy to determine the reference compensating current. Fig. 3 depicts the Simulink model of the current control algorithm.

It can be seen from the above analysis that the delay resulting from the proposed algorithm is less than half of the main cycle, which is half of that of DFT and the same as that of the algorithm based on IRPT. Besides, the algorithm proposed could detect the positive/negative-sequence fundamental current, active/reactive power component of positive-sequence fundamental current, and selective harmonics expediently, which is more flexible than the algorithm based on IRPT and DFT.

\section{Simulation setup}

Purpose of the simulation is to show the usefulness of the proposed SAPF control strategy. Two test cases are taken into consideration with different source voltages and load conditions. In case 1 , the source voltages are sinusoidal and balanced with a magnitude of $230 \mathrm{~V}$ and a frequency of $\omega=100 \pi$ and the source supplies an imbalanced nonlinear load. In case 2, imbalanced / distorted source voltages supply an imbalanced nonlinear load in parallel with an imbalanced load.

\subsection{Simulation Results for Sinusoidal, Balanced Source Voltages}

The balanced and sinusoidal three phase voltages considered are, $\mathrm{V}_{\mathrm{a}}=230 \sin (\omega \mathrm{t}), \mathrm{V}_{\mathrm{b}}=230 \sin \left(\omega \mathrm{t}-120^{\circ}\right), \mathrm{V}_{\mathrm{c}}=250 \sin$ $\left(\omega \mathrm{t}+120^{\circ}\right)$.

The load used is a bridge rectifier which acts as a nonlinear imbalanced load. The simulation results have been plotted separately for a clear study.

Fig.4, Fig 5, Fig 6, exhibit the source voltage, line current, reference compensation current and source current after compensation for the three phases respectively.

Fig 6 depicts the source voltage, load current and the source current after compensation. Simulation results of compensation current generated by the controller are shown in Fig. 7

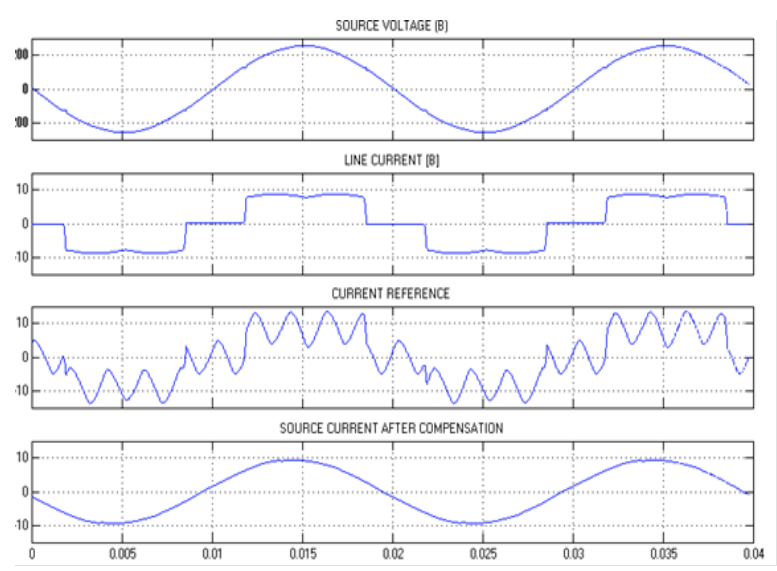

Fig. 4. After compensation phase A. 


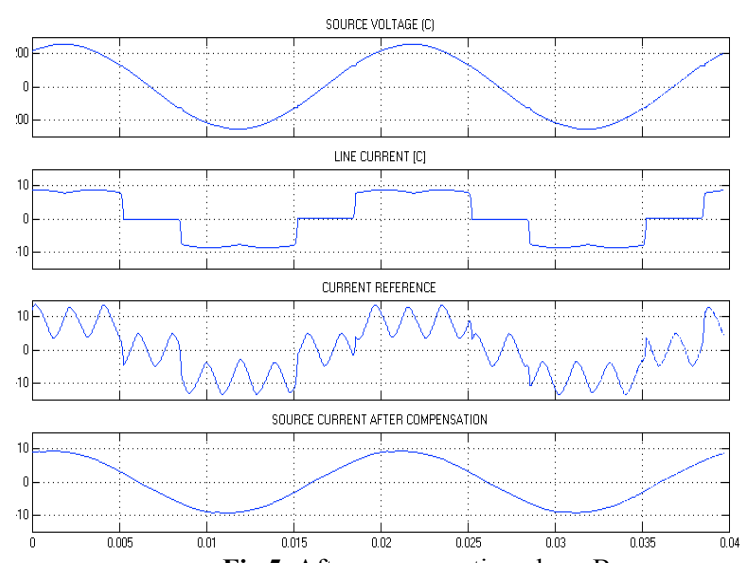

Fig 5. After compensation phase B.
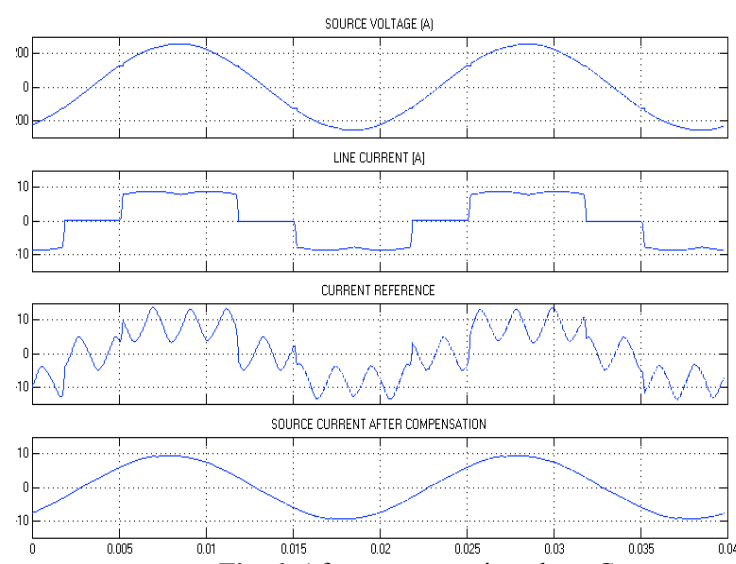

Fig. 6. After compensation phase C.
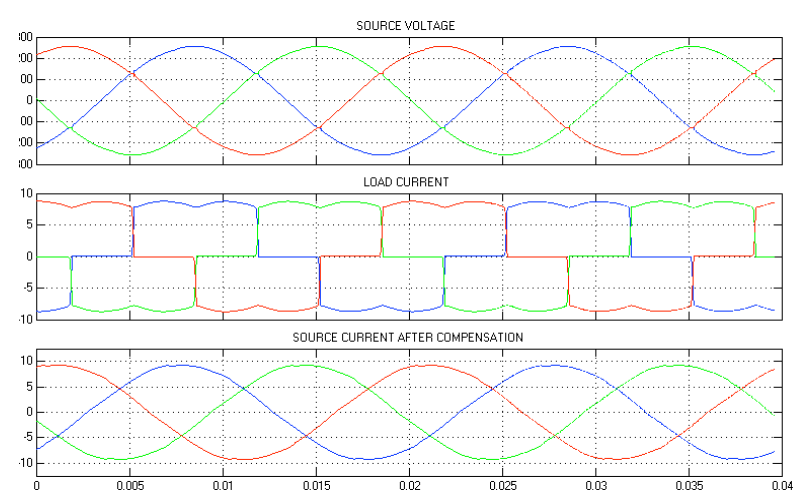

Fig. 7. Source voltage, load current and source current after compensation.

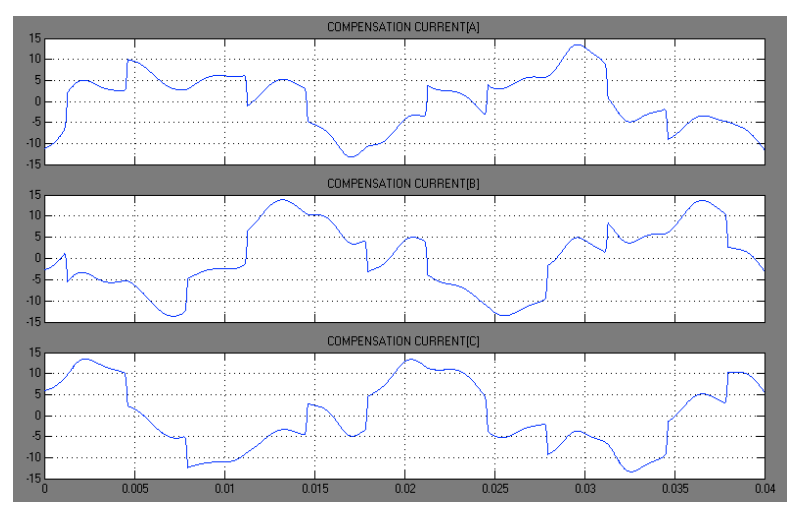

Fig. 8. Compensation current.

\subsection{Analysis of Simulation Results}

The simulation results are available for two cases considered. From Fig. 8 it is clear that the SAPF injects harmonic currents into the line thereby making the input supply sinusoidal.

The comparison of THD is given in Table 1 for the three reviewed and available methods namely Generalized Instantaneous Reactive Power Theory based methods, Synchronous Reference Frame method and the Synchronous Current Detection methods. From the results Fig. 9 it observed that for balanced source voltages the THD for the proposed method is less than the available methods and also the delay resulting from the proposed algorithm is less than half of the main cycle, which is half of that of DFT and the same as that of the algorithm based on IRPT.
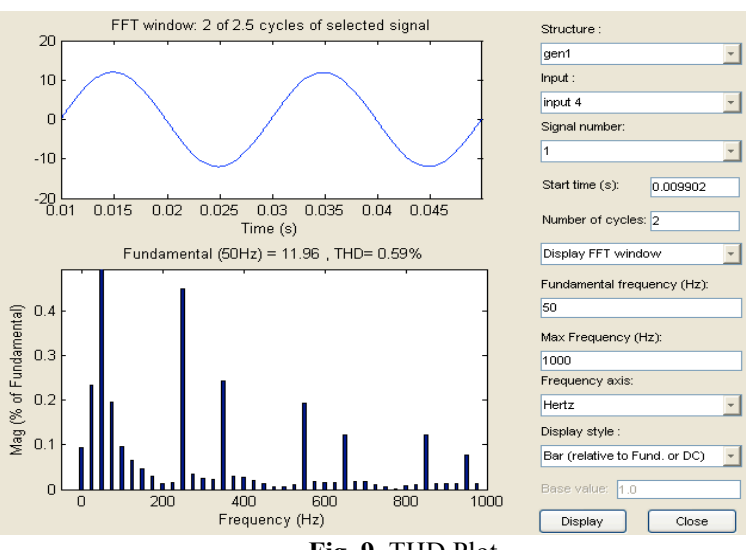

Fig. 9. THD Plot

Table 1. The comparison of THD.

\begin{tabular}{lc}
\hline $\begin{array}{l}\text { Reference compensation } \\
\text { current calculation }\end{array}$ & $\begin{array}{c}\text { \% THD of source } \\
\text { current balanced supply } \\
\text { voltage }\end{array}$ \\
\hline GIRPT method & 1.87 \\
SRF method & 3.60 \\
SCD Method & 0.98 \\
Proposed method & $\mathbf{0 . 5 9}$ \\
\hline
\end{tabular}

\section{Conclusion}

This paper has outlined the mathematical modeling and design of the reference compensation current controllers for shunt active power filters based on time domain approach in detail. The simulation results of the proposed method are compared with that of the available results of Generalized Instantaneous Reactive Power Theory based method, Synchronous Reference Frame method and the Synchronous Current Detection methods. From the results it can be concluded that the delay resulting from the proposed algorithm is less than half of the main cycle, which is half of that of DFT and the same as that of the algorithm based on IRPT. From the analysis and simulation it is found that the algorithm presented in this thesis has the advantages of flexibility, accuracy and easy implementation. Since the reference compensation currents are determined in the 'a-bc' reference frame, there is no reference frame transformation is required. Therefore, it results in less complexity in realizing the control circuit of SAPF and still maintains good filter performance. After SAPF injects the 
compensation currents, it is found that the source currents become ideal and remain in phase with the positivesequence fundamental source voltages. Therefore, the utility source power factor at the positive sequence fundamental frequency is achieved and the harmonic currents are well controlled. The Total Harmonic Distortion (THD) study reveals that the proposed method has a source current THD less than the available methods. The proposed compensation strategy of the SAPF is verified through MATLAB/Simulink which yields good agreement with the expected SAPF goals.

\section{References}

1. H. Akagi, Y. Kanazawa, and A. Nabae, "Generalized theory of the instantaneous reactive power in three-phase circuits," in Proc. IEEJ Int. Power Electron. Conf., Tokyo, Japan, 1983, pp. 1375-1386.

2. H. Akagi and A. Nabae, "Instantaneous reactive power compensators comprising switching devices without energy storage components," IEEE Trans. Ind. Appl., vol. 20, no. 2, pp. 625-630, Mar./Apr. 1984.

3. A. A. Girgis, W. B. Chang, and E. B. Makram, "A digital recursive measurement scheme for on-Line tracking of power system harmonics," IEEE Trans. Power Del., vol. 3, pp. 11531160, Jul. 1991.H. Akagi, "New trends in active filters for power conditioning," IEEE Trans. Ind. Appl., vol. 32, no. 3, pp. 13121322, May/Jun. 1996.

4. G. Chen ,Y. Chen and K.M. Smedley, "Three-phase four-leg active power quality conditioner without references calculation ,"in Procd. IEEE APEC '04, vol.1, pp.587-593, 2004.

5. Vadirajacharya Kumar, P. Agarwal and H.O.Gupta, "A Simple Control Strategy For Unified Power Quality Conditioner Using Current Source Inverter,"in Procd. IPEC2007, pp.1219-1223.

6. K. Viswanathan, D. Srinivasan, and R. Oruganti, "Design and analysis of SISO fuzzy logic controller for power electronic converters," in Proc. IEEE Int. Conf. Fuzzy Syst., 2004, vol. 3, Jul. 25-29, 2004, pp. 1293-1298.

7. S. K. Jain, P. Agrawal, and H. O. Gupta, "Fuzzy logic controlled shunt active power filter for power quality improvement," Proc. Inst. Elect Eng., Electr. Power Appl., vol. 149, no. 5, 2002.

8. Filter for Selective Harmonic Compensation"; IEEE 2003

9. J. M. Correa, F. A. Farret, J. R. Gomes, and M. G. Simoes, "Simulation of Fuel Cell Stacks Using a Computer Controlled Power Rectifier with the Purposes of Actual High Power Injection Applications", IEEE Trans. Ind. Applicat., Vol. 39, No. 4, pp. 1136-1142, 2003.
10. N. J. Bershad, M. Bermudez, and J. Y. Tourneret, "An affine combination of two LMS adaptive filters-transient mean-square analysis," IEEE Trans. Signal Precessing, vol. 56, pp. 1853-1864, May 2008.

11. Gao Ying, Xie Shengli, "A variable step size LMS adaptive filtering algorithm and its analyses," Acta Electronica Sinica, vol. 29, pp. 87-90,August 2001.

12. G. Escobar, P. Mattavelli, and A. Stankovic, "An adaptive control for UPS to compensate unbalance and harmonic distortion using a combined capacitor/load current sensing," IEEE Trans. Ind. Electron, vol. 54, pp. 839-847, April 2007.

13. B. M. Han, B. Y. Bae, and S. J. Ovaska, "Reference signal generator for active power filters using improved adaptive predictive filter," IEEE Trans. Industrial Electronics, vol. 52, pp. 576-584, 2005.

14. Liu Hui, Liu Guohai, and Shen Yue, "A novel real-time harmonic detection method using fast lifting wavelet transform," Journal of Jiangsu University(Natural Science Edition), vol. 30, pp. 288-292, May 2009.

15. M. EI-Habrouk and M. K. Darwish, "Design and implementation of a modified Fourier analysis harmonic current computation technique for power active filters using DSP's,," Proc. Inst. Elect. Eng.-Elect. Power Appl., vol. 148, no. 1, pp. 21-28, Jan. 2001.

16. V. Kaura and V. Blasko, "Operation of a phase locked loop system under distorted utility conditions," IEEE Trans. Ind. Appl., vol. 33, no. 3, pp.58-63, May/Jun. 1997.

17. H. Li, F. Zhuo, andW. Lei, "Control system of the multiple large power rate active power filter," Adv. Tech. Elect. Eng. Energy, vol. 23, no. 1, pp.25-28, Jan. 2004.

18. J. R. Varquez and P. Saimeron, "Active power filter control using neural network technologieds," Proc. Inst. Elect. Eng.-Elect. Power Appl., vol.150, no. 2, pp. 139-145, Mar. 2003. 